\title{
The Effect Of Special Exercises Using Assistive Devices To Build A Movement Program According To Some Biokinetic Variables In Teaching The Performance Of The Shooting Skill From The Angle, Opposite The Throwing Arm In Handball For Junior
}

\author{
Thaer awad jabar ${ }^{1}$, Hayder shamky jabar \\ ${ }^{1}$ College of Physical Education and Sports Sciences, University of Thi-Qar .
}

\begin{abstract}
Objectives of the study: Preparing special exercises using auxiliary means according to the values of some biomechanical variables to teach the performance of the shooting skill from the angle, unlike the preferred side of the junior handball. Knowing the effect of special exercises using auxiliary means on the values of some Biokinetic variables in teaching the skill of shooting from the corner, unlike the preferred side of the junior handball.

Conclusions: The results showed the effectiveness of using special exercises according to the mechanical foundations of the angle shooting skill, unlike the preferred side of the hand ball for emerging players through the high level of shooting accuracy as a result of the development in the level of the series of biomechanical variables in the pre and post tests and in favor of the post test.The special exercises contributed directly to the development of the variables and characteristics of the strength characteristic, which showed in the development of values (the lowest strength in the absorption stage, the time of the lowest strength in the absorption stage, the maximum strength in the rise stage, and the area under the curve).

Recommendations: The necessity to focus on the biomechanical laws that basically control every stage of performance, the skill of correcting from the angle, through what these values achieved in terms of moral differences that have effectively contributed to the high level of performance and with less effort.
\end{abstract}

Keywords: special exercises, assistive devices, build a movement program, Biokinetic variables, shooting skill, angle, throwing arm, handball for junior .

\section{Chapter 1}

Introduction and importance of research

\subsection{Introduction of the study:}

The world witnessed a tangible development in high sporting achievements, and innovations in technical and written performance in most sporting events thanks to the positive employment of other sciences. Team games have become a field of attraction for practitioners, viewers and researchers, and handball is one of the group games that have taken on its modern look, similar to the rest of the fields of sports competitions. It has become evident that these fields are moving rapidly from changes and developments in their laws and performance requirements, trying to keep pace with the development of the rest of the branches of human knowledge in order to serve the goals of sport in the pleasure of playing and watching and the high level of competition.

Handball is one of the differential games that, like other sports, require diversity in training methods that would raise the level of technical performance of the basic skills of this game, especially the skill of shooting of all kinds, being the main goal that is the final outcome of all offensive skills, which is the boundary between winning and losing In matches.

Modern handball depends on the corner player, so the coaches at the present time have paid attention to the high level of this center player to take advantage of this gap in the defense row to end attacks away from the defensive density in the middle of the field by mastering the corner player for all kinds of correction.

Hence the importance of research in building a new dynamic program according to the 
principle of the learning effect transmission from the preferred party to the non-preferred party by relying on building exercises according to principles, laws, Biokinetic principles and economics by effort, and thus accessing the performance of the correction skill from the corner, unlike the preferred party for the emerging players, to the technical performance required to reach To the best level.

\subsection{The problem of the study:}

The development of the physical and tactical level and modern play has led to a clear development in the defensive lines, which deals with situations that the opponent does not expect, including rotating the playing centers until penetration of the defense zone became a difficult matter in the center and forearm in general and the corner center in particular.

Through the researcher's follow-up of the field, local matches, and his experience as a player, inquiring with expertise, specialists, and coaches of the game, as well as reviewing the sources and research that studied the game, both Arab and foreign, he noticed that there is a clear imbalance in the angle area, the researcher summarized it in several points:

1- The lack of the left-wing player, which constitutes a clear defect in the attack in the rightwing area and to a lesser extent the left-wing area.

2- Injury to the players during matches, which causes the coaches to suffer from the lack of an alternative, especially for the left-handed player.

3- Pause for two minutes and exclusion cases.

Accordingly, all the problems that the researcher dealt with in terms of problems prompted the coach to seek the help of the right player and play against the aiming arm and vice versa for the left player, which is a weakness in the level in general and a clear imbalance in this position.
Therefore, the researcher decided to study this problem through the use of special exercises using auxiliary means to build a new movement program according to the principle of transferring the learning effect from the preferred party to the non-preferred party according to the foundations and Biokinetic principles to try to raise the level of performance of the shooting skill from the corner for emerging players, unlike the preferred party.

\subsection{Objectives of the study:}

1- Preparing special exercises using auxiliary means according to the values of some biomechanical variables to teach the performance of the shooting skill from the angle, unlike the preferred side of the junior handball.

2- Knowing the effect of special exercises using auxiliary means on the values of some Biokinetic variables in teaching the skill of shooting from the corner, unlike the preferred side of the junior handball.

\subsection{Hypotheses of the study:}

1- The presence of statistically significant differences in the values of some Biokinetic variables of the angle correction skill, in contrast to the preferred side of the handball in the post test.

2- Special exercises have a positive effect on teaching the skill of shooting from the angle, unlike the arm aiming the junior handball.

\subsection{Research limits:}

1.5.1 The human limits: The specialized center players in Zi- Qar Governorate.

1.5.2 The temporal limits: the period from $(1 / 9 / 2020)$ to $(1 / 4 / 2021)$

1.5.3 Spatial limits: Hall of the martyr Haider Kamel Burhan.

\section{Chapter II}

2- Theoretical studies and previous studies:

\subsection{Learning and motor learning:}




\subsubsection{Learning:}

Scientists and researchers differed in their definition of the educational process or the learning process, and from the definitions that were repeated in many references, which clarify that learning "is a natural phenomenon that can take place as a natural response to the stimuli of the environment, as the organism modifies its behavior and thinking in order to achieve for itself a compatibility with those stimuli." (1).

Before delving into the clarification of the exact meaning of learning, the terms learning and education must be clarified, as these two terms are two sides of the same coin, whose goal is the completion and development of the educational process, and they cannot be separated, due to their coherent connection. "Learning symbolizes the concepts and principles on which the learning process and the variables are based. It concerns the individual and the learner, while education is based on practical applications, and harnessing the concepts and principles of learning through educational uses directed and guided by the learner from the teacher or trainer "(2).

Both Daris \& Burton (1992) and Griffy(1991)) argue that "there is a strong correlation between teaching and student learning", and "indicators of understanding and understanding the learning process are essential indicators for developing effective education" (3).

The term modern learning "is the individual's ability to realistically deal with knowledge and its real and effective use at the appropriate time and place, and this knowledge interact positively between itself and work, that is, the interaction between action and thinking to reach the ideal state of performance" (4). This does not mean only the skillful performance, but it includes the motor and physical performance, and it appears on achievement to achieve the goal of the educational process, and learning in this sense is preparation between educational ability and rapid transfer between understanding, application and performance, and here the similarity equation must be present, meaning there must be Dialogue and similarity in trends and ideas to reach the goal.

\section{2-1-2 Concept of Learning Impact Transition:}

The transmission of the learning effect is one of the internationally known phenomena in the applications of learning in the fields of education, education and medical rehabilitation, and in educational systems. It is considered an important part of the curriculum and the development of education. Magill, A. Richard (2004) defines the transmission of the learning effect "as the effect of previous experience in performing a new skill with its content" (5). (Rink 2006) adds to it a definition that the transmission of the learning effect "is a concept attributed to the effect of one learned skill or the learned ability and its transfer to other skills and abilities" (6). It also explains that the learning effect transmission is an important phenomenon for teachers because it is the way for the teacher to design the curriculum and the way to organize the successive series of skills training and that the teacher aims from that to promote positive transmission and reduce negative transmission (7), and the types of transmission will be explained later. skills:

\section{1-5 Kinetic analysis of mathematical}

"This method is concerned with searching for the hypothetical correlation between the effect of force and the different types of movements as well as researching the negatives of movement by studying the forces that affect the movement. To achieve this, force recording devices that exploit the resistance of the earth as an external force that are related to the reactions of the muscular force acting in It is concerned with studying the forces affecting the movement and how to deal with these forces, considering that the movement is a mutual effect between the internal (muscle) forces and the external forces, 
such as the force of earth attraction and the force of water thrust (8).

There are several purposes for kinetic analysis in the mathematical field, which are (9):

1. Analysis for the purpose of identifying the technical characteristics of the skill.

2. Analysis for the purpose of detecting performance defects.

3. Analysis for the purpose of comparing performance with optimal performance, or the socalled theoretical curves.

4. Analysis for the purpose of theoretical study of the movements of the models.

\section{2-1-6 Shooting with Hand Reel: -}

Correction skill is the borderline between victory and defeat, but the various offensive skills and plans of play become useless if they are not finished and culminate in the end with successful correction on the goal (10).

Correction: is the final result of the attack in the hope of scoring a goal as the goal of the attack system is to create a suitable position in which one of the team members can take a direct goal throw with a good chance to score (11).

Correction is affected by several factors, including (12):

Correction angle: The more you shoot from the area facing the target, the more successful it will be.

Distance: The shorter it is, the more accurate it will help him to aim.

- Guidance: The more the ball is directed at critical corners or areas for the goalkeeper, the more difficult it is for him to block it, and the wrist contributes a lot to directing the ball.

Speed: The faster the setting, the more likely the aim is.

\section{Chapter III}

3- Research methodology and field procedures:

\section{1-3 Research Method:}

Practical research has varied and with it the approaches, because the value of the research and its results are closely related to the approach that the researcher follows, and therefore the current research problem required the application of special exercises to develop the skill of correction from the corner with the hand reel unlike the preferred party, and that the research problem is of an experimental nature, so it is selfevident that The researcher follows the one-group experimental approach, as it is one of the most appropriate approaches to research, "as this approach allows us to know the value of the effect of the independent variable on the dependent variable by observing any change in the dependent variable" (13).

\subsection{Research community and sample:}

For the purpose of conducting the research and implementing its vocabulary in an accurate scientific manner, the research sample must be chosen from the original community, as the researcher applies the steps and vocabulary of his research on them, and the selection of the sample is a great necessity from the main scientific research vocabulary, and the sample is the "model on which the researcher conducts the whole and the focus of his work" (14).

The research community included the players of the Specialized Center for juniors' Handball in Dhi Qar Governorate, whose ages range from (14-15) years and totaling (10) players. (5) Players were chosen by the deliberate method, representing $(50 \%)$ of the original community.

\subsection{Sample homogeneity:}

For the purpose of verifying the homogeneity of the sample, the researcher performed some procedures to control the variables even though the selected sample is of close age group.

Therefore, statistical methods were used by means of the arithmetic mean, standard deviation, and coefficient of variation for morphological measurements and biomechanical variables to find out the reality of the difference or not. Table (1) illustrates this. 
It is proved that the value of the coefficient of variation is less than $30 \%$ and the sources should be remembered that whenever the coefficient of variation is less than $30 \%$, this means that the sample is homogeneous.

Table (1): The homogeneity of the study sample is shown in age, height and weight using the coefficient of variation, which shows values less than $30 \%$

\begin{tabular}{|c|l|c|c|c|c|}
\hline No & \multicolumn{1}{|c|}{$\begin{array}{c}\text { Measurments and } \\
\text { varaibles }\end{array}$} & Unit & Mean & S.D & $\begin{array}{c}\text { Coefficient of } \\
\text { variation }\end{array}$ \\
\hline 1 & Age of training & Month & 4 & 0,7 & $\% 17,5$ \\
\hline 2 & Mass & $\mathrm{Kg}$ & 59 & 2,4 & $\% 4,06$ \\
\hline 3 & Length & $\mathrm{Cm}$ & 165 & 6,67 & $\% 4,04$ \\
\hline 4 & $\begin{array}{l}\text { Maximum force in thrust } \\
\text { stage }\end{array}$ & Newton & 934 & 25,51 & $2,74 \%$ \\
\hline 5 & $\begin{array}{l}\text { Time of maximum power } \\
\text { in the thrust stage }\end{array}$ & second & 0,23 & 0,02 & $\% 8,69$ \\
\hline 6 & $\begin{array}{l}\text { The lowest strength } \\
\text { recorded is in the } \\
\text { absorption stage }\end{array}$ & Newton & 697 & 12,04 & $\% 1,72$ \\
\hline 7 & $\begin{array}{l}\text { Time of the lowest } \\
\text { strength recorded in the } \\
\text { absorption stage }\end{array}$ & second & 0,43 & 0,01 & $\% 2,32$ \\
\hline 8 & \begin{tabular}{l} 
An area under the curve \\
\hline
\end{tabular} & Newton / & 126,77 & 1,15 & $\% 0,90$ \\
\hline
\end{tabular}

\section{3 - 4 Tools, means and devices used in the} study:

Research tools are "the means by which the researcher can collect data and solve his problem to achieve the research objectives, regardless of the tools with data, samples and devices" (15).

\subsubsection{Data collection methods:}

- Arab and foreign sources and references.

- Personal interviews

A questionnaire form to view the opinions of specialized experts to choose the appropriate test.

Observation and analysis

\subsubsection{Instruments and devices used in the} research:
- A Japanese-made CASIO video camera with a frequency of 300 images / second, counts (3).

- A laptop computer.

CDs.

- Software and applications used in a computer for kinematic analysis. (Kenova)

- A device for measuring height, weight.

- A legal handball court.

- Balls.

\section{3-5 biokinetic variants:}

It included the following variables:

1. The maximum force in the thrust stage: It is the maximum amount of force that the player exerts during the rise stage, and it is measured in units (Newton). 
2. The time of the maximum strength in the thrust stage: It is the time that the force takes for the time the player relies on the podium to the moment of leaving it, and is measured in units (second).

3. The lowest force recorded in the absorption stage: It is the smallest value recorded on the curve in the absorption stage, and it is measured in units (Newton).

4. The time of the lowest force recorded in the absorption stage: It is the time that the force lasts from the moment of the lowest force to reaching the maximum force, and it is measured in units (second).

5. Area under the curve: It is the amount of the impact of the momentum between the two moments of the beginning and the end of the final thrust, or the momentum that is equal to the momentum that equals the change in the amount of movement and is measured in units (Newton / second). (16)

\section{3-6 field research procedures:}

\section{3-6-1 Tests and pre-imaging of the study} sample:

The researcher conducted the tests and premeasurement of the experimental group before starting to implement the exercises on 9/1/2020 at nine in the morning (in the closed hall for sports at the College of Physical Education and Sports Sciences - Zi- Qar University). The assistant work staff and all the members of the research sample of (5) players attended, after which all the requirements for the experiment were prepared, where the researcher used three cameras, and the location of the cameras was located where the first camera was placed at a point located $(715 \mathrm{~m})$ from The player's starting point, while the lens's focus height from the ground was $(1.25 \mathrm{~m})$ and the second camera position was $(9.25 \mathrm{~m})$ from the player's starting point, and the focus height of the lens from the ground was $(1.25 \mathrm{~m})$ and the third camera was at $(8,25)$ So that the cameras showed the player's movement from the moment of approaching to the moment of correction and landing, and the power platform was placed in its designated place on the rise area, and a scale of (1 $m)$ length was used to find out the real value that appears in the film. The area of $(6 \mathrm{~m})$ to the place where the player landed inside the goal area, then the researcher and the supervisor explained the method of performing the shooting accuracy test from the angle against the aiming arm, and before starting the shooting process, an adequate warmup period was given to the members of the research sample and after that the experiment was performed and all the attempts were filmed It has been implemented by the players and has been analyzed The attempt that records the highest degree of accuracy.

\section{7- Tests and post-imaging of the study sample:}

The post-test of the research sample was conducted on the day of 5/2/2021 in the closed hall for sports at the College of Physical Education and Sports Sciences - Zi-Qar University) after the completion of the curriculum application period, which took (12) weeks, and the researcher was keen to provide the test conditions The tribal and its procedures used to test the technical performance of the skill of correction from the angle, unlike the preferred side of the handball.

3-8 statistical methods:

The researcher used the statistical methods that helped in addressing the results and testing of the research hypotheses through the use of the statistical bag (spss 24):

- Arithmetic mean.

- Standard deviation.

- Coefficient of variation.

- Pearson correlation coefficient.

-T-test for correlated samples.

- Percentage.

\section{Chapter IV}

4- Presentation, analysis and discussion of the results: 
4-1 Presenting and analyzing the results of the biochemical variables and discussing them when performing the shooting skill from the corner, unlike the preferred side for the pre and post -test:

Table (2): It shows the values of the arithmetic mean, the standard deviations, the (T) value calculated for the values of some biochemical variables, and the accuracy of the pre and post test

\begin{tabular}{|c|c|c|c|c|c|c|c|c|}
\hline \multirow{2}{*}{ Result } & \multirow{2}{*}{ Sig } & \multirow{2}{*}{$\begin{array}{c}\mathbf{T} \\
\text { value }\end{array}$} & \multicolumn{2}{|c|}{ Post } & \multicolumn{2}{|c|}{ Pre } & \multirow{2}{*}{ Biokinetic variables } & \multirow[b]{2}{*}{ No } \\
\hline & & & S.D & mean & S.D & mean & & \\
\hline $\begin{array}{l}\text { signific } \\
\text { ant }\end{array}$ & $\mathbf{0 , 0 1}$ & 9,84 & & 1063 & & 934 & Maximum force in thrust stage & .1 \\
\hline Not sig & 0,14 & 1,82 & $\mathbf{0 , 0 1}$ & 0,21 & $\mathbf{0 , 0 2}$ & $\mathbf{0 , 2 3}$ & $\begin{array}{r}\text { Time of maximum power in the } \\
\text { thrust stage }\end{array}$ & .2 \\
\hline $\begin{array}{c}\text { signific } \\
\text { ant }\end{array}$ & $\mathbf{0 , 0 0 3}$ & 6,67 & 8,25 & 709 & 12,04 & 697 & $\begin{array}{r}\text { The lowest strength recorded is } \\
\text { in the absorption stage }\end{array}$ & .3 \\
\hline Not sig & $\mathbf{0 , 0 0}$ & 12,94 & $\mathbf{0 , 0 1}$ & $\mathbf{0 , 3 7}$ & $\mathbf{0 , 0 1}$ & $\mathbf{0 , 4 3}$ & $\begin{array}{l}\text { Time of the lowest strength } \\
\text { recorded in the absorption stage }\end{array}$ & .4 \\
\hline $\begin{array}{l}\text { signific } \\
\text { ant }\end{array}$ & $\mathbf{0 , 0 0 1}$ & 5,01 & $\mathbf{0 , 9 3}$ & 129,81 & 1,15 & 126,77 & An area under the curve & .5 \\
\hline
\end{tabular}

Biokinetic variables that include the components of the characteristics of the (strength time) curve of the skill of aiming from the angle against the preferred side were extracted by computer and through the force measurement platform (Force Plat Form). The results of the pre and post -tests of the search group appeared as shown in Table (13), as the nature of The research group investigated differences between values of some biochemical variables. The results were treated statistically by (T) test for correlated samples, and through Table (13) the variables were presented and analyzed as follows:

1- The maximum force in the thrust stage and the time to reach it:

The arithmetic mean of the variable reached the maximum power in the push stage of the shooting skill from the angle, unlike the preferred side in the pre-test (934), and the arithmetic mean of the time reached in the pre-test was $(0.23$ seconds) and with a standard deviation (0.02) in When the arithmetic mean of the maximum power variable was in the push stage of the shooting skill from the angle, in contrast to the preferred side in the post test (1063), the arithmetic mean of its arrival time was $(0,21$ seconds $)$ and with a standard deviation $(0,01)$ and when testing $(\mathrm{T})$ For the related samples, it appeared that the value of (T) for the variable of momentum force $(9,84)$ and the level of significance (0.001), while the value of $(\mathrm{T})$ for the variable of arrival time was (1.82) and with the level of significance (0.14). There are significant differences in the thrust variable and not significant for its time in the performance of the shooting skill from the angle, unlike the preferred side.

2- The lowest strength in the absorption stage and the time to reach it:

The arithmetic mean of the lowest force variable in the absorption stage of the angle's aiming skill, unlike the preferred side in the pretest was (697 Newtons) with a standard deviation of (12.04), and the arithmetic mean of the time reached in the pretest was ( 0.43 seconds) and with a standard deviation (ll 01 ) while the arithmetic 
mean of the lowest strength variable in the absorption stage of the angle shooting skill was unlike the preferred side in the post test (709) and with a standard deviation $(8,25)$ and the arithmetic mean of its arrival time was ( 0.37 seconds) and with a standard deviation ( 0 When performing a (T) test for the correlated samples, it appeared that the value of $(\mathrm{T})$ for the variable of absorption strength was $(6,67)$ with a significance level $(0,003)$, while the value of $(\mathrm{T})$ for the variable arrival time was (12.94) and with the level of significance $(0,01)$ and through the foregoing, we see the emergence of significant differences in the variable of the lowest absorption force and its time in the performance of the aiming skill from the angle against the preferred side.

The researcher attributes this development in the post-test to the research group, which had a positive and effective effect of the exercises used that increase strength and increase efficiency, which would develop explosive force and the characteristic force of velocity of the legs that may have given a clear indication of the development of strength. Studies have shown that "there is a positive relationship. Between the ability of handball players to jump and the man's mass index, strength and its associated physical characteristics are highly correlated with high performance (player height) during correction, and that strength improves as a result of regular training, especially if this training contains appropriate jumps and training methods for jumping Suitable for the capabilities of the players with the graduation in these loads according to the improvement of their abilities (17).

And the result of the approximate steps for the appropriate situation of the movement requirements, the transfer of force is from one part of the body to the point where the result is in correcting the ball, "the kinetic chain formed by extending the joints of the body from the bottom to the top will leave its effect on the speed of the ball launch" (18).
The researcher believes that the shorter the time of the less force (absorption), the greater its output and this affects the time of the maximum force, which is the total time of movement, so its output is greater and its speed is greater. So the player can get a big push through a large force in a small time, and here the importance of the exercises used on the absorption stage (upon support) and then the movement appears, as the lowest absorption force is one of the most critical moments of the stage affecting the technical performance and preparing for the payment requirements as a result of the increased load on The driving man, which requires an increase in the exerted force at the end of the absorption stage, for its effective relationship in the total driving force, so we find it the most important influence on the level of technical performance.

As Gerd Khumuth asserts, "The path of force - time in the preliminary stage of the jump is heading downwards and related to the center of body mass, so it is exposed to a halt through the positive force heading upwards, so the muscle strength must be greater than the subjective weight and in this way a positive force is actually available, which is what It is called the initial force, and it is the lowest position of the body mass center, that is, at the beginning of the jump movement itself. "(19)

As the arrival time of the lowest force of absorption mediates the times of the first and final thrust phases, and this time is very important in the thrust process because the thrust is the product of the force in time. Therefore, the time of the absorption phase will match the time of the thrust phase, which consequently affects the time of the total thrust, so the player must $\mathrm{He}$ is keen on synchronizing the use of the force that he harnesses through the appropriate bending and stretching and transferring it through the joints of the body within the flow of movement in time and with good compatibility.

That force has a prominent role in achieving good results when practicing sports, especially 
with regard to the production of force at the appropriate moment and speed, as the concentration of force with increasing its speed is one of the characteristics of good skillful performance (20).

\section{3- Area under the curve:}

The arithmetic mean of the area variable under the curve for the high crushing skill in the pre-test was (126.77 Newton / second) with a standard deviation of (1.15), while the arithmetic mean of the area variable under the curve for the high crushing skill in the post test was (129.81 Newton / second) With a standard deviation (0.93) and when testing $(\mathrm{T})$ for the correlated samples, it appeared that the calculated value of $(\mathrm{T})$ was (5.01) and with a significant level (0.001). Through the above, we see that there are significant differences that appeared in the variable of an area under the curve in the performance of the skill of overwhelming high and in favor of Post- test.

The researcher attributes this development to the exercises used that work to develop the explosive power, as the thrust equals an area under the curve and with a different unit, so they express the same situation and since the area under the curve is an instantaneous force, it is collected and found its rate and then multiplied by the total time, the thrust Equals the rate of force in time (21).

From the above, the researcher believes that the increase in the amount of force (momentum) during the movement resulting from an increase in the angle of the knee joint led to an increase in the area under the curve for correction from the angle. The increase in the effect of the temporal force and whoever exerts the maximum possible force from the beginning of the movement to the end of the movement achieves a greater content under the curve "(22).

The content of the incident area defined for the force-time curve increased with the increase in thrust change (23). Note that the area under the curve increases according to the magnitude of the absolute force (24). Muscle force before the start of the jump balances the force of gravity in the starting position, meaning that the resultant force is equal to zero, but as soon as the amount of muscle force exceeds the body weight (ground gravitational force) meaning The result of the force becomes positive and moves upward, the movement begins, and by continuing to increase the strength of the muscles, the body accelerates sharply meaning its speed increases, as the joints were bent before the start of the movement and then began to stretch during the movement, but it will reach its full extension with the end of the push and this means the end of the force effect And that the body at this moment has reached its maximum speed and since the body falls under the influence of the force of gravity almost only during flight and this works to stop the movement, the result becomes negative (25).

\section{Chapter V}

\section{5- Conclusions and recommendations}

\section{5-1 Conclusions:}

1. The results showed the effectiveness of using special exercises according to the mechanical foundations of the angle shooting skill, unlike the preferred side of the hand ball for emerging players through the high level of shooting accuracy as a result of the development in the level of the series of biomechanical variables in the pre and post tests and in favor of the post test.

2. The special exercises contributed directly to the development of the variables and characteristics of the strength characteristic, which showed in the development of values (the lowest strength in the absorption stage, the time of the lowest strength in the absorption stage, the maximum strength in the rise stage, and the area under the curve).

3. There is a positive effect in the transmission of the learning effect from the preferred party to the non-preferred party and this 
is evident through the significant differences in the pre and post -tests in favor of the post test.

4. The similar movement in the kinematic response as well as the players' previous experience gained in the skill of shooting from the corner contributed to the facilitation of the transmission of the learning effect from the preferred party to the non-preferred party.

\section{2-5 Recommendations:}

1. The necessity to focus on the biomechanical laws that basically control every stage of performance, the skill of correcting from the angle, through what these values achieved in terms of moral differences that have effectively contributed to the high level of performance and with less effort.

2. Conducting research and studies on the transmission of the learning effect from the preferred party to the non-preferred party in the skill of correction from the angle on other Sunni groups.

3. Conducting research and studies on the transmission of the learning effect between individual and group gaming skills.

\section{References:}

[1] Iman Shaker Mahmoud Analysis of the relationship between the characteristics of the (force - time) curve of some biomechanical variables for the stage of advancement in the effectiveness of the long jump: (PhD thesis, University of Baghdad / College of Physical Education, 1993).

[2] Jabbar Abdel-Hamid and Ahmed Khairy Kazem: Research Methods in Physical Education and Psychology: (Cairo, Dar AlNahda Al-Arabiya, 1973).

[3] Jamal El-Din Abdel-Aty: Programmed learning in physical education and sports, Arab Thought House, Cairo, 1979.

[4] Gerd Khumuth (translation) Kamal Abdel Hamid and Salman Ali Hassan: Biomechanics and Scientific Research
Methods for Mathematical Movements, Book Center for Publishing, Cairo, 1999.

[5] Hussein Mardan Omar, Iyad Abdul Rahman: Biomechanics in Sports Movements, 1st Edition, Najaf Al Ashraf Press, 2011.

[6] Siddiq Tulan: The effect of developing the strength distinguished by speed on improving the performance level of some movements of the promotion group in gymnastics, $\mathrm{PhD}$ thesis, College of Physical Education for Boys, Alexandria, 1980.

[7] Diaa Al-Khayyat Nofal Muhammad, Handball, 1st Edition, (Mosul University, Mosul University Press, 2001)

[8] Zafer Hashem Ismail: Interdisciplinary teaching style and its effect on learning and development through spatial organizational options for the tennis education environment. PhD thesis, College of Physical Education, University of Baghdad, 2002

[9] Abdul Wahab Ghazi Handball is about what it has to do with educational and training principles, 1st Edition, (Baghdad, Al-Omran Press, 2008).

[10] Ali Muhammad Abd al-Rahman and Talha Hussain Husam al-Din; Mathematical Kinesiology and Foundations of Kinetic Analysis. Cairo: Arab Thought House, 1994.

[11] Imad al-Din Abbas, Medhat Mahmoud, The Applications of Offensive in Handball, Teaching-Training, 1st Edition, (Egypt, Zagazig University, 2007).

[12] Muhammad Hassan Allawi and Osama Kamel Ratib: Scientific Research in Physical Education and Sports Psychology: (Cairo, Arab Thought House, (1999).

[13] Mohamed Youssef Al-Sheikh: Biomechanics and its Applications, Dar Al Ma'aref, Egypt, 1986, p. 254.

[14] Wajih Mahjoub: Methods of Scientific Research and its Methods, 2nd Edition, 
Baghdad, Dar Al-Hikma for Printing and Publishing, 1988.

[15] Essam El-Din Metwally Abdullah: Kinetics and Biomechanics between theory and practice, 1st Edition, Dar Al-Wafaa for the World of Printing and Publishing, Alexandria, 2011.

[16] Peen, X., G. 1994: The effect of depth jump and weight training on vertical jump Research guarterly, sports medicine, Vol. 72, No. 1

[17] Glenn S. Fleisig, PhD 2010, American Sports Medicine Institute, (Saint Vincents Drive),p.52

[18] Ibid; p.36.

[19] Magill, A. R.; Motor learning and control, Concepts and application, $7^{\text {th }}$ ed., Boston, Mc-Graw Hill, 2004, p.231 .

[20] Rink, E. Judith; Teaching Physical Education for Learning, $5^{\text {th }}$ ed., Boston, McGraw Hill, 2006, p.36 .

\section{Footnotes:}

1- Jamal al-Din Abd al-Ati: Programmed learning in physical education and sports, Arab Thought House, Cairo, 1979, p.9.

2- Zafer Hashim Ismail: Interdisciplinary teaching style and its effect on learning and development through spatial organizational options for the tennis education environment. $\mathrm{PhD}$ thesis, College of Physical Education, University of Baghdad, 2002 p.10.

3- Sindetop (1991) Davis \& Burton (1992), Griffy (1991): Quoted by David, J, Langley Student Human Kinetics Publisher Cognition in instructional Setting. Journal of Teaching Ph. Ed. Inc., Champaign, Illinois, U.S.A.,1995, (15), pp. $25-40$.

4- Zafer Hashem Ismail: The same source, 2002, p.10.

5-Magill , A. R.; Motor learning and control, Concepts and application, 7th ed., Boston, Mc-Graw Hill, 2004, p.231 .
(3) 6- Rink, E. Judith; Teaching Physical Education for Learning, 5th ed., Boston, Mc-Graw Hill, 2006, p.36 .

7- Ibid; p.36.

8-Adel Abdul-Basir; The previous source, $\mathrm{p}$. 161.

9-Ali Muhammad Abd al-Rahman and Talha Husam al-Din; Mathematical Kinesiology and Foundations of Kinetic Analysis. Cairo: Arab Thought House, 1994, p. 210.

10- Imad al-Din Abbas, Medhat Mahmoud, Applications of Attack in Handball TeachingTraining, 1st Edition, (Egypt, Zagazig University, 2007) p.29

11- Abd al-Wahhab Ghazi; Handball has its money and what it has to do with educational and training principles, 1st Edition, (Baghdad, AlOmran Press, 2008) p.102.

12- Diaa Al-Khayyat Nofal Muhammad, Handball, 1st Edition, (Mosul University, Mosul University Press, 2001) p. 40.

13- Jabbar Abdel-Hamid and Ahmed Khairy Kazem: Research Methods in Physical Education and Psychology: (Cairo, Dar Al-Nahda AlArabiya, 1973), p.20.

14- Muhammad Hassan Allawi and Usama Kamel Ratib: Scientific Research in Physical Education and Sports Psychology: (Cairo, Arab Thought House, (1999, p. 140).

15- Wajih Mahjoub: Methods and Methods of Scientific Research, 2nd Edition, Baghdad, Dar Al-Hikma Printing and Publishing, 1988, p. 133.

16- Iman Shaker Mahmoud; Analysis of the relationship between the characteristics of the (force - time) curve of some biomechanical variables for the stage of advancement in the effectiveness of the long jump: ( $\mathrm{PhD}$ thesis, University of Baghdad / College of Physical Education, 1993) p. 44.

17- Peen, X., G. 1994: The effect of depth jump and weight training on vertical jump 
Research guarterly, sports medicine, Vol. 72, No.

1

18- Glenn S. Fleisig, PhD 2010, American Sports Medicine Institute, (Saint Vincents Drive),p.52

19-Gerd Khumuth (translation) Kamal Abdel Hamid and Salman Ali Hassan: Biomechanics and Scientific Research Methods for Mathematical Movements, Book Center for Publishing, Cairo, 1999, p. 318

20-Siddiq Tulan: The effect of developing the strength distinguished by speed on improving the performance of some movements of the promotion group in gymnastics, $\mathrm{PhD}$ thesis, College of Physical Education for Boys, Alexandria, 1980, p. 30.

21- Hussein Mardan Omar, Iyad Abdul Rahman: Biomechanics in Sports Movements, 1st Edition, Najaf Al Ashraf Press, 2011, p. 139.

22- Sawsan Abdel Moneim and others: a previously mentioned source. 1977, p.221.

23- Gerd Hochmuth: A previously mentioned source, p. 317.

24- Muhammad Yusuf al-Sheikh: Biomechanics and its Applications, Dar Al Ma'arif, Egypt, 1986, p. 254.

25-Essam El-Din Metwally Abdullah: Kinetics and Biomechanics between Theory and Practice, 1st Edition, Dar Al-Wafaa for the World of Printing and Publishing, Alexandria, 2011, pg. 170 